\title{
Reforming Australia's Federal Framework: Priorities and
}

\section{Prospects}

\begin{abstract}
Anne Tiernan
A narrative of failure permeates debates about Australia's federal system. A cursory review of analysis and particularly of media commentary, reveals a deep pessimism about this central and distinctive feature of Australia's governing framework (see, among numerous potential examples, National Commission of Audit 2014).
\end{abstract}

Elite disdain towards Australia's system of shared powers and a tendency to overlook its many strengths, has limited the scope and ambition of federal reform processes. That these are usually initiated and driven by the Commonwealth perhaps accounts for complaints from sub-national governments that the dynamics of these processes often mirror those that characterise Commonwealth-State relations, with the result that it is difficult to transcend the tensions that are borne of the centralisation of money and power that reform needs to address.

Our nation's founders chose federalism, along with the Westminster tradition of responsible government, as the constitutional framework most suited to the goal of uniting six independent, diverse, and geographically dispersed colonies to form the Commonwealth of Australia. Their achievement was no mean feat. This fusion helped overcome entrenched parochial and political barriers to achieve federation in 1901 and the understandable concerns the large and small colonies each had about the costs and trade-offs to be made in exchange for the benefits of collective strength and nationhood. The federalism movement, which positioned Australia internationally as a democratic innovator (Wright 2014), faced many challenges and setbacks along the path to federation. Intense political and public debates were 
held to develop the federal model and marshal the support necessary to achieve democratic endorsement of the Australian Constitution. Over more than two decades, a series of meetings, conventions, and referenda was held to try to reconcile the divergent interests. The outcome, a political compromise and far from perfect, sought to balance unity with diversity, efficiency with flexibility, and the national with the international and local by preserving the authority and independence of democratic and self-sufficient colonies (Williams 2013).

Much has changed in the period since 1901. The demands of globalisation and regionalism have revived interest in federalism. In searching for political arrangements and institutional structures capable of accommodating diversity and difference, while offering strength and scale in national unity, both established and emerging democracies have chosen federalism. Australia's federal system has served the nation well (Twomey and Withers 2007), but within the federal structure, the dynamics among Commonwealth, state, and territory governments and the allocation of responsibilities and resources are constantly evolving. A combination of High Court decisions in favour of the Commonwealth, the loss of a viable revenue base for the states and territories, and the related tendency for federal governments to intervene in areas of traditionally state responsibility have led to an unusual degree of centralisation in the Australian federation (Koutsogeorgopulou and Tuske 2015; Williams 2013).

For the past 15 years, a succession of serving and former sub-national leaders has sought to catalyse the debate about the changes needed to address the trend to centralisation in Australia's federal framework, particularly the vertical fiscal imbalance and mechanisms to address power asymmetries among Commonwealth, state, and territory governments. 1 More recently, they have been joined by a litany of individuals and organisations, including the Productivity Commission, Institute of Public Administration Australia, Committee for the Economic Development of Australia (CEDA), and others, which have all argued the need for 
urgent reforms to the Australian federation.2 Tony Abbott described the federation as ‘Australia's biggest political problem', while the Business Council of Australia (2006) has estimated that eliminating duplication and overlap and 'ending the blame game' among the tiers of government could save in the order of \$20 billion a year, or 3\% of GDP.

This consensus, and the central focus on fiscal repair, provided the context for Tony Abbott's election commitment that a coalition government would produce a white paper on reform of the federation. Connected with, but separate to a proposed white paper on taxation, from the Commonwealth Treasury, the white paper on reform of the federation would seek to clarify roles and responsibilities among Commonwealth, state, and territory governments. Within the existing constitutional framework, it would seek to address common criticisms and concerns about current federal arrangements. Its specific objectives would be to do the following:

- $\quad$ reduce and end, as far as possible, the waste, duplication, and second-guessing among the different levels of government;

- achieve a more efficient and effective federation, and in so doing, improve national productivity;

- make interaction with the government simpler for citizens;

- ensure our federal system is better understood and valued by Australians (and the case for reform supported);

- has clearer allocation of roles and responsibilities;

- enhances government's autonomy, flexibility, and political accountability; and

- $\quad$ supports Australia's economic growth and international competitiveness. (Department of the Prime Minister and Cabinet (PM\&C) 2014: v).

A taskforce based in the PM\&C was responsible for working with state and territory governments to produce the white paper. It led the development of five 'Issues Papers' 
addressing key areas for reform including roles and responsibilities in housing and homelessness, health, education, the governance of COAG and federal financial relations.3

The white paper's Terms of Reference set out six 'design principles' against which proposals for reallocating roles and responsibilities among the different tiers of government in each of these areas would be assessed. These included the following:

- accountability for performance in delivering outcomes;

- $\quad$ subsidiarity;

- national interest considerations;

- equity, efficiency, and effectiveness of service delivery;

- durability; and

- fiscal sustainability.

The Communiqué from Abbott's first meeting as Chair of COAG in December 2013 set the tone for more collaborative and respectful relationships than had existed under the Howard, Rudd, and Gillard governments. It noted:

"The Commonwealth respects the States and Territories are sovereign in their own sphere. They should be able to get on with delivering on their responsibilities, with appropriate accountability and without unnecessary interference from the Commonwealth."

But the bonhomie and aspirations of those who welcomed the white paper process were, like so much of the Abbott government's agenda, derailed by its first budget. Significant, unilateral cuts to federal funding in the areas of health and education focused state and territory leaders' attention on the looming threat to their fiscal sustainability and capacity to deliver adequate levels of service without significant reforms to federal financial relations. It 
became increasingly apparent the decision to separate the federation and tax reform processes was impeding progress towards meaningful reform. With criticism mounting of Tony Abbott's commitment to and management of the white paper process, and growing concern about declining competitiveness and productivity in the Australian economy, the prime minister appointed an Expert Advisory Panel 'to provide advice and contribute to public discussion on aspects of the White Paper'.

Fiscal pressures and furious disagreement about the distribution of GST revenue set the scene for a rancorous COAG meeting in April 2015. Away from the theatre and ritual, however, leaders accepted their shared responsibility to achieve change and agreed that 'the goal of federation reform is to improve the living standards and wellbeing of all Australians' (COAG Communiqué, 17 April 2015). COAG acknowledged the important context for the federation discussions was the budgetary pressure for all states and territories and the Commonwealth due to expected growth rates in health and education expenditure and the adequacy of the revenue base over time. Leaders noted that any federation reform would need the states, territories, and Commonwealth to work together to meaningfully address these long-term funding pressures and also look at structural reforms to ensure services can be delivered in the most efficient way. Governments would need to be certain they would have appropriate revenue to meet their responsibilities. The communiqué recorded this would be a key consideration of both the tax and federation white papers, which are being progressed together, but analysts wondered how and at what point, the two processes would be linked (see, e.g. Brown 2015).

The April meeting concluded with the agreement that a 'Leaders' Retreat' would be convened in July 2015 to debate federal reform. The communiqué reported that leaders had 'ambitious discussions about ways in which the Commonwealth state governments can 
cooperate more effectively to make major improvements in the delivery of services to all Australians'. Noting the fact that no election was scheduled for 16 months presented a unique reform opportunity, leaders unanimously agreed to focus reform on health, education, infrastructure, and housing. The communiqué, drafted by leaders themselves, gave responsibility to individual premiers and chief ministers for specific streams of work on reform proposals to be considered at their November meeting. Acknowledging the 'fiscal gap', particularly around health expenditure, leaders emphasised that 'despite these reforms, there will be a significant gap between the resources necessary to maintain and improve services into the future, and the revenue currently available' (Australian Leaders' Retreat Communiqué, 23 July 2015).

Tony Abbott's intransigence about the fiscal gap and his refusal to allow a broad-ranging debate about how revenue might be increased posed an insurmountable challenge for premiers confronting a looming crisis in 2017-2018. It hardened elite opinion that the prime minister was incapable of achieving necessary reforms and that his partisan instincts represented a threat to Australia's competitiveness and prosperity.4 Malcolm Turnbull reflected these sentiments when he outlined his rationale for challenging Abbott's leadership:

... the Prime Minister has not been capable of providing the economic leadership our nation needs; he has not been capable of providing the economic confidence that business needs. We need a ... style of leadership that respects the people's intelligence, that explains these complex issues, and then sets out the course of action we believe we should take, and makes a case for it. We need advocacy, not slogans. We need to respect the intelligence of the Australian people. (Turnbull 2015.)

Malcolm Turnbull's unexpected ascension to the Australian prime ministership in September 2015, and his commitment to put all reform options on the table, is a potential game-changer 
for the reform of Australia's federation. Although commissioned before the leadership challenge, and intended to inform the reform process currently underway, the contributions to this Special Issue are even more salient now.

\section{An Overview of Articles}

Articles in this collection seek to challenge the narrative of failure, and to question whether a broader range of perspectives can inform our understanding of Australian federalism - its performance (broadly connoted) and its potential. Our contributors map the scope and scale of the reform challenge, and highlight the complex interdependencies inherent to the delivery systems that are the primary focus for the proposed reforms. Some of them are provocative challenging the fundamental precepts of the process initiated under Tony Abbott. For example, Adrian Kay questions whether the goal of redefining roles and responsibilities among the tiers of government - the central focus of the white paper on reform of the federation, is relevant or necessary. He posits that the concept of multi-level governance (MLG) offers a more analytically useful way of understanding the capacity for and barriers to dynamism and innovation in the Australian federation; and of accommodating economically and territorially diverse and divergent policy challenges.

Derived originally from studies of the European Union, MLG focuses on the vertical and horizontal dimensions of policy coordination in governance contexts where 'formal powers are concurrent, overlapping, or simply ambiguous, but where there is a powerful vertical interdependence in the control of governing resources or policy instruments'. According to Kay, the MLG concept places experimentation and innovation in policy coordination across different spatial levels at its analytical core. What matters is the quality of interactions between the different jurisdictions. These often occur without reliance on explicit hierarchy, 
are informal and based on trust relationships, and, in the most effective cases, reflect a shared commitment to problem solving.

From an MLG perspective then, the appeal to sovereignty at the heart of the current white paper process is 'curious'. Kay argues that sovereignty - if read as meaning clearly delineated constitutional roles and responsibilities - does not imply capability. To be sovereign is not the same as being functional in a public administration and policy sense - as recent policy failures reflecting overly centralised and prescriptive policy direction from Commonwealth governments - can attest. Given the lack of a general theory of Australian federalism, Kay argues MLG can add analytic value to the concept of 'pragmatic federalism' advanced by Hollander and Patapan (2007). As this suggests, a potentially more useful focus for the white paper might be how roles and responsibilities in key policy areas can be shared among the different tiers of government in different parts of Australia, according to local capacity and jurisdictional competence.

The principle of subsidiarity is one of the six design principles reflected in the white paper on federal reform. Issues Paper 1: A Federation for Our Future (PM\&C 2014: 20) defines subsidiarity as meaning 'that responsibility for particular areas should rest with the lowest form of social organization capable of performing the function effectively'. But as the trend to centralism has shown, subsidiarity has been difficult to operationalise within Australia's federal arrangements. Deem, Brown, and Hollander posit this may be because attitudes towards and commitment to the principle varies, particularly between officials from Commonwealth and sub-national jurisdictions, who have responsibility for policy design and implementation.

Their article investigates public servants' perceptions of subsidiarity, drawing on data from the Australian Constitutional Values Survey (ACVS). These findings are supplemented by 
qualitative data that explore officials' attitudes towards subsidiarity when confronted by practical issues in the policy areas of health, education, environment, and roads and highways. The authors propose that a 'pragmatic' approach to subsidiarity may help to cut through differences of opinion revealed in their data, and provide a more useful framework for operationalising the principle of subsidiarity in the planning and execution of federal reform.

This brings us to the most vexing and contested problem of reforming the federation: federal financial relations and options for ensuring the tiers of government each have sufficient revenue to meet their spending commitments. This issue sits at the nexus of the federation reform and tax white paper processes. It proved difficult to make meaningful progress while the Abbott government insisted Australia's budget problems were mostly on the expenditure rather than the revenue side. However, at the Leaders' Retreat it was agreed that 'taken in parallel with the Tax White Paper ... there is an opportunity to consider more durable revenue arrangements to address growing financial pressures facing all governments (Australian Leaders' Retreat Communiqué, 23 July 2015, 2).

In their contribution to this Special Issue, Richard Eccleston and Helen Smith examine issues and options for state tax reform, as sub-national governments ponder over the consequences of the Commonwealth's 2014/15 Budget decision to freeze (in real terms) tied grants to the states. The centralised nature of Australia's federal financial relations and the relatively high vertical fiscal imbalance is well recognised (see, e.g., Koutsogeorgopulou and Tuske 2015), as are constraints on state own-source revenue. The authors ask whether this unilateral costshifting action by the Commonwealth - unprecedented in Australia's federal history - heralds an era of 'fend-for-yourself federalism'. 
Eccleston and Smith trace two sets of economic developments that have exacerbated existing tensions within federal financial relations. These include the mining boom, the so-called 'two-speed economy', and fiscal and budgetary consequences of the global financial crisis. Revenue is declining for all Australian governments, while expenditure continues to grow, particularly in the large delivery systems for which sub-national governments have primary responsibility. Reflecting the key criteria of adequacy and efficiency in state funding, the authors canvas three options: broadening and increasing the rate of the Goods and Services Tax (GST), income tax sharing or increasing the Medicare levy, and finally broadening state land tax. They argue a comprehensive reform program encompassing consumption, income and land tax is needed to create sustainable funding arrangements for Australian governments, and note the new prime minister's early efforts to build consensus for tax reform offers signs for cautious optimism.

The domain of housing policy is the oldest and most enduring arena of Commonwealth-state cooperation in the Australian federation. In their paper, Walter and Holbrook survey the history of housing policy and ask what lessons can be learned from various cycles of Commonwealth involvement that might have relevance for the current federal reform process. Their narrative history is presented as a means of clarifying the 'wicked' policy challenges for, and intentions of, policy makers in this complex area. They conclude that the housing policy story is one of the incremental attempts to more tightly define and target who should benefit from government policy. They posit that Geyer's (2012) metaphor of a 'complexity cascade' offers a feasible and more precise way of mapping of the dimensions of complexity and can assist in future policy deliberation. This complexity is reflected in the disjuncture between the reforms proposed in the Issues Paper on housing and homelessness, which focuses on disadvantage and homelessness and public debate about 'the housing problem', which is concerned with housing affordability and intergenerational disadvantage. 
The current reform of the federation process has required significant cooperation among officials from Commonwealth, state, and territory jurisdictions, who have met constantly since the process was initiated in 2014. Glyn Davis and Helen Silver are both former participants in the crucial, but little-examined, field of intergovernmental relations, where senior officials support negotiations between political leaders and 'bargain in the margins' of COAG meetings to help achieve agreement on collaborative reform. Their paper reflects on the lessons from the National Competition Policy (NCP) reforms of the 1990s and the more recent Intergovernmental Agreement on Federal Financial Relations (IGA FFR), drawing on interviews with key protagonists.

Davis and Silver contrast the success of the NCP reforms with the rushed and less enduring experience of the IGA FFR. They conclude key variables for success include: clear problem definition and agreement about reform objectives and adequate time to build the evidence base and resolve technical issues. They also note the importance of process - of trust and formal and informal negotiations between officials in the continuous process of negotiation required to achieve intergovernmental agreement. Their contribution highlights the importance of governance issues raised in Issues Paper Five on COAG and federal financial relations, which have received comparatively little attention in public debate. A senior state official said recently that 'Incentives matter. The negotiating environment entirely favours the Commonwealth'. There is an urgent need to reform the institutional architecture that supports COAG, and to confront the political economy of Commonwealth-state relations, which mirrors the imbalance in the federation that derives from the vertical fiscal imbalance.

\section{Conclusion}


Pragmatism is a recurrent theme in this collection, as is the critical importance of relationships - among leaders, the senior officials who support them, and the frontline staff of all tiers of government engaged in implementing and delivering policy and programs within Australia's federal framework. The contributions to this Special Issue highlight that proposed reforms to address the trend to centralism and inherent power asymmetries that characterise Australian federalism are behavioural and cultural as much as constitutional (see Menzies 2014). Unless and until the habits and cultures of politicians and officials in intergovernmental relations can be reset - to something more collaborative and invested in shared problem solving, and supporting architecture embedded through reform of federal financial relations and the governance of COAG and IGR, we are unlikely to achieve desired reforms.

There is a broad consensus that there is an urgent need to reform Australia's federation, but to date, the process has been an elite debate among policymakers, officials, a small group of scholars, stakeholders, and other (often self-appointed) experts. In being largely Commonwealth-led and narrowly focused on economic and fiscal concerns, rather than assessing the democratic and other governance strengths and weaknesses of federation, the white paper on federal reform process contrasts to the processes that led to the Constitution of Australia being drafted and endorsed. There has been little acknowledgement of key precepts of federal systems: the strengths to be found in diversity and difference, checks and balances on power, opportunities for innovation and policy learning across jurisdictional boundaries. Importantly, the vexed issue of revenue and how the white papers on federation reform and tax will reconcile and intersect remains unclear.

In an address to the recent IPAA National Conference, former SA premier and member of the Expert Advisory Panel, Dr John Bannon claimed that 'academics are very negative about this 
[the Federation Reform] process'. This jarred with my experience of frequent engagement by the small band of Australian federalism scholars with the long history of attempts to reform the federation, at the State and Commonwealth levels. To the extent the papers in this collection are provocative or critical, it is because the issues are complex and warrant more extensive and transparent democratic engagement than the current process has offered. Like many state and territory leaders, and perhaps too, the new prime minister, scholars want reforms to the federation to be more ambitious, rigorous, and inclusive.

The articles in this collection underscore the importance of Australian scholars studying and analysing their own national politics, and the value and impact these studies can have for contemporary policy-making. The editors hope that through their contributions, scholars too can lend their passion and leadership to the task of reforming Australia's federation, as Mike Baird exhorted officials to in his Garran Oration. It is hoped the issues raised here will support policymakers to achieve COAG leaders' commitment that the goal of federation reform is to improve the living standards and well-being of all Australians.

\section{References}

Banks, G. 2012. Productivity Policies: The ‘To Do’ List. Economic and Social Outlook Conference, 'Securing the Future', Melbourne, 1 November.

Beattie, P. 2001. Governance in Australia's System of Federalism. Queensland Government. Beattie, P. 2007. Speech at the Executive Speak Luncheon, Edinburgh Room, Brisbane Club. 4 September.

Brown, A. J. 2015. ' New Formula Needed for Sharing Responsibility.' The Australian. 14 October.

Brumby, J. and B. Galligan . 2015. ' The Federalism Debate.' Australian Journal of Public Administration 74( 1): 82-92. 
Business Council of Australia. 2006. ' Reshaping Australia's Federation: A New Contract for Federal-State Relations.' Available from http://www.bca.com.au/publications/reshapingaustralias-federation-a-new-contract-for-federal $\%$ E2\%80\%93state-relations.

Business Council of Australia. 2013. 'Action Plan for Enduring Prosperity.' Available from http://www.bca.com.au/publications/action-plan-for-enduring-prosperity-read-the-plan-andgive-your-feedback.

Committee for Economic Development of Australia. 2014. 'A Federation for the $21^{\text {st }}$ Century.' Available from http://www.ceda.com.au/research-andpolicy/research/2014/10/27/federalism.

Department of the Prime Minister and Cabinet. 2014. ' Reform of the Federation White Paper. Issues Paper 1: A Federation for our Future.' Available from http://federation.dpmc.gov.au/issues-paper-1.

Geyer, R. 2012. ' Can Complexity Move UK Policy Beyond 'Evidence-Based Policy Making' and the 'Audit Culture'? Applying a 'Complexity Cascade' to Education and Health Policy.' Political Studies 60( 1): 20- 43.

Hollander, R. and H. Patapan. 2007. ' Pragmatic Federalism: Australian Federalism from Hawke to Howard.' Australian Journal of Public Administration 66( 3): 280- 297. Koutsogeorgopulou, V. and A. Tuske. 2015. ' Federal-State Relations in Australia.' OECD Economics Department Working Papers No. 1198. Paris: OECD Publishing. Available from http://www.oecd-ilibrary.org/economics/federal-state-relations-in-australia_5js4h5mx7bg0en.

Menzies, J. 2011. ' Blowing Hot and Cold - Intergovernmental Relations Capacity in the Commonwealth Government.' Australian Journal of Public Administration 70( 4): 408- 420. 
Menzies, J. 2014. ' The Culture of Commonwealth and State Relations.' In A Federation for the $21^{\text {st }}$ Century (pp. 64-70). Melbourne: Committee for the Economic Development of Australia.

National Commission of Audit. 2014. ' Towards Responsible Government: The Report of the National Commission of Audit Phase One.' Available from http://www.ncoa.gov.au/report/docs/phase_one_report.pdf. Turnbull, M. 2015. ‘ Doorstop Interview on Liberal party Leadership.’ Available from http://www.malcolmturnbull.com.au/media/transcript-doorstop-interview-canberra1. Twomey, A. and G. Withers. 2007. ' Federalist Paper 1: Australia's Federal Future.' A Report for the Council for the Australian Federation. Available from http://www.caf.gov.au/Documents/AustraliasFederalFuture.pdf. Williams, G. 2013 ‘ Australia's Federal Future, Sir Samuel Griffith Series.' Available from https://www.griffith.edu.au/sir-samuel-griffith-legacy-series.

Wright, C. 2014 “" A Splendid Object Lesson’: A Transitional Perspective on the Birth of the Australian Nation." Journal of Women's History 26( 4): 12-36. 